\title{
Enhancer of Zeste 2 Polycomb Repressive Complex 2 Subunit Is Required for Uterine Epithelial Integrity
}

Xin Fang, ${ }^{*}$ Nan Ni, ${ }^{*}$ John P. Lydon, ${ }^{\dagger}$ Ivan Ivanov, ${ }^{\ddagger \S}$ Kayla J. Bayless, ${ }^{\oplus}$ Monique Rijnkels, ${ }^{*}$ and Qinglei Li ${ }^{*}$

From the Departments of Veterinary Integrative Biosciences* and Veterinary Physiology and Pharmacology ${ }^{\ddagger}$ and the Center for Translational Environmental Health Research, ${ }^{\S}$ Texas A\&M University, College Station; the Department of Molecular and Cellular Biology, ${ }^{\dagger}$ Baylor College of Medicine, Houston; and the Department of Molecular and Cellular Medicine, ${ }^{\Uparrow}$ Texas A\&M University Health Science Center, College Station, Texas

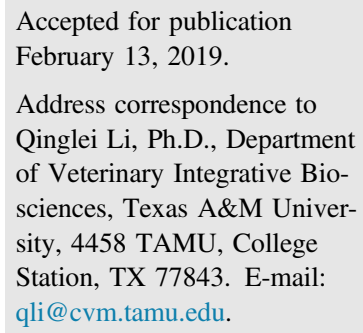

\begin{abstract}
Normal proliferation and differentiation of uterine epithelial cells are critical for uterine development and function. Enhancer of zeste 2 polycomb repressive complex 2 subunit (EZH2), a core component of polycomb repressive complexes 2, possesses histone methyltransferase activity that catalyzes the trimethylation of lysine 27 of histone $\mathrm{H} 3$. EZH2 has been involved in epithelial-mesenchymal transition, a key event in development and carcinogenesis. However, its role in uterine epithelial cell function remains unknown. To determine the role of uterine EZH2, Ezh2 was conditionally deleted using progesterone receptor Cre recombinase, which is expressed in both epithelial and mesenchymal compartments of the uterus. Loss of EZH2 promoted stratification of uterine epithelium, an uncommon and detrimental event in the uterus. The abnormal epithelium expressed basal cell markers, including tumor protein 63, cytokeratin 5 (KRT5), KRT6A, and KRT14. These results suggest that EZH2 serves as a guardian of uterine epithelial integrity, partially via inhibiting the differentiation of basal-like cells and preventing epithelial stratification. The observed epithelial abnormality was accompanied by fertility defects, altered uterine growth and function, and the development of endometrial hyperplasia. Thus, the Ezh2 conditional knockout mouse model may be useful to explore mechanisms that regulate endometrial homeostasis and uterine function. (Am J Pathol 2019, 189: 1212-1225; https://doi.org/ 10.1016/j.ajpath.2019.02.016)
\end{abstract}

The endometrium of the uterus comprises both luminal and glandular epithelia, the integrity of which is critical for uterine function. In mice, the proliferation of luminal epithelium is reduced before blastocyst implantation; and high proliferative activity of luminal epithelium, resulting from imbalanced hormonal signaling, prevents blastocyst implantation. ${ }^{1}$ Enhanced uterine epithelial proliferation has also been linked to endometrial hyperplasia, a premalignant condition of endometrial cancer. ${ }^{2}$ It was shown that uterine epithelial stratification, arising from ablation of fibroblast growth factor receptor 2 (FGFR2), causes pregnancy complications. ${ }^{3}$ The murine endometrium contains slightly coiled glands that are formed postnatally. ${ }^{4}$ Uterine glands play an indispensable role in mice during pregnancy via the production of secretory substances that regulate uterine receptivity and decidualization. ${ }^{5,6}$ The requirement of uterine glands in pregnancy was also demonstrated by using the ovine uterine gland knockout model. ${ }^{7}$ Furthermore, the importance of uterine gland secretions in mouse pregnancy was shown by studies using uterine-specific knockout mice of forkhead box A2 (Foxa2), in which the production of leukemia inhibitory factor essential for implantation is impaired. ${ }^{8}$

Polycomb group proteins are conserved epigenetic regulators of gene silencing and cell fate determination and maintenance. ${ }^{9}$ Two major polycomb group complexes, polycomb repressive complex (PRC) 1 and PRC2, have been characterized in mammals. The core subunits of PRC2 consist

Supported by the Eunice Kennedy Shriver National Institute of Child Health and Human Development/NIH grant R01HD087236 (Q.L.) and a Texas A\&M University T3 grant (Q.L.).

Disclosures: None declared. 
of enhancer of zeste 2 PRC 1 or 2 subunits (EZH1 or EZH2, respectively), SUZ12 polycomb repressive complex 2 subunit, and embryonic ectoderm development. ${ }^{10}$ Among these proteins, EZH2 is a well-established histone methyltransferase, catalyzing the trimethylation of lysine 27 of histone $\mathrm{H} 3$ $(\mathrm{H} 3 \mathrm{~K} 27)^{10}$ or functionally interacting with DNA methyltransferases. ${ }^{11}$ EZH2 regulates a wide spectrum of physiological and pathologic events, including, but not limited to, cell differentiation, germline development, X-chromosome inactivation, stem cell pluripotency, cell-cycle progression, DNA repair, and cancer development. ${ }^{12-15}$

Evidence supports a link between altered expression of EZH2 and in vitro decidualization of human endometrial cells, ${ }^{16}$ environmental estrogen exposure ${ }^{17}$ uterine fibroids, ${ }^{15}$ endometriosis, ${ }^{18}$ and endometrial cancer development. ${ }^{19}$ However, the role of EZH2 in normal uterine epithelial cells remains undefined. Our results reveal that loss of EZH2 produces basal-like epithelial cells or a cell population expressing basal markers in the uterus, signifying the importance of epigenetic regulators in the female reproductive tract.

\section{Materials and Methods}

\section{Animals and Tissue Collection}

The animal use protocol was approved by the Texas A\&M University (College Station, TX) Institutional Animal Care and Use Committee. Animals were handled according to the animal care and use guidelines from the NIH's Guide for the Care and Use of Laboratory Animals ${ }^{20}$ and the Texas A\&M University Institutional Animal Care and Use Committee. Mice were housed under a 12-hour light/12-hour dark cycle in the Laboratory Animal Resources and Research facility. Animal care was provided by experienced technicians from the Comparative Medicine Program. Mice were on a C57BL/6; 129SvEv background. Generation of progesterone receptor $(P g r)-$ Cre mice ${ }^{21}$ and $E z h 2^{\text {flox/flox }}$ mice ${ }^{22}$ was described previously. The $E z h 2^{\text {flox/flox }}$ mice were purchased from The Jackson Laboratory (Bar Harbor, ME; stock number 022616). Vaginal smears were analyzed to confirm the cycling, and all mice used in this experiment had intact ovaries. Uterine epithelia were collected by a mild trypsin digestion, ${ }^{23}$ followed by mechanical separation using fine forceps under a stereo dissection microscope (Olympus, Waltham, MA). Uterine samples used for histologic studies were fixed with $10 \%(\mathrm{v} / \mathrm{v})$ neutral-buffered formalin (Millipore Sigma, St. Louis, MO). Samples were embedded and processed using the on-campus Core Histology Laboratory of the Veterinary Integrative Biosciences Department. Hematoxylin and eosin staining was used to determine general histopathological features of the reproductive tract.

\section{Generation of Mice with Uterine Conditional Knockout of Ezh2}

Control $\left(E z h 2^{\text {flox/flox }}\right.$ Ctrl $)$ and $E z h 2$ conditional knockout $\left(E z h 2^{\text {flox/flox }} ; \mathrm{Pgr}^{\mathrm{Cre} /+} ; E z h 2 \mathrm{cKO}\right)$ mice were generated. The genotype of mice was analyzed by genomic PCR based on an established The Jackson Laboratory protocol using mouse tail DNA and primers Ezh2 flox-forward (5'-CATGTGCAGCTTTCTGTTCA- $\left.3^{\prime}\right)$ and $E z h 2$ flox-reverse $\left(5^{\prime}-\right.$ CACAGCCTTTCTGCTCACTG-3') (wild-type band $=203$ $\mathrm{bp}$, and flox band $=$ approximately $300 \mathrm{bp}$ ). The primers used to amplify the recombined/mutant $E z h 2$ band (200 bp) were 5'-CCCATGTTTAAGGGCATAGTGACATG-3' (forward) and $5^{\prime}$-TCGAGGGACCTAATAACTCGTATAGCA- ${ }^{\prime}$ (reverse). ${ }^{22}$ Hypoxanthine guanine phosphoribosyltransferase (Hprt) was used as an internal control. ${ }^{24}$ Genotyping of $P g r$-Cre and analysis of PCR products were described elsewhere. ${ }^{25,26}$

\section{Immunohistochemistry and Immunofluorescence}

Immunostaining was detailed previously. ${ }^{26,27}$ Briefly, paraffin sections $(5 \mu \mathrm{m}$ thick) were deparaffinized, rehydrated, and boiled in citrate buffer $(\mathrm{pH}=6)$ to expose the

Table 1 Information of Primary Antibodies

\begin{tabular}{llll}
\hline Name & Manufacturer & Catalog number & Host \\
\hline EZH2* & Cell Signaling (Danvers, MA) & Rabbit \\
FOXA2 & Abcam (Cambridge, MA) & 5246 & $1: 400$ \\
Ki-67 & Abcam & Ab108422 & Rabbit \\
VIM & Cell Signaling & Ab16667 & Rabbit \\
ACTA2 & Cell Signaling & 5741 & Rabbit \\
KRT8 & DSHB (Iowa City, IA) & $1: 200$ \\
KRT14 & Thermo Fisher Scientific (Waltham, MA) & 19245 & Rabbit \\
KRT14 & Santa Cruz Biotechnology (Dallas, TX) & TROMA-I & Rat \\
KRT5 & Biolegend (San Diego, CA) & PA5-16722 & Rabbit \\
KRT6A & Biolegend & SC-53253 & Mouse \\
$\Delta$ Np63 & Biolegend & 905501 & $1: 200$ \\
\hline
\end{tabular}

*Western blot analysis: 1:1000

ACTA2, $\alpha$-smooth muscle actin; DSHB, Developmental Studies Hybridoma Bank; EZH2, enhancer of zeste 2 polycomb repressive complex 2 subunit; FOXA2, forkhead box A2; IF, immunofluorescence; IHC, immunohistochemistry; KRT, cytokeratin; $\Delta$ Np63, tumor protein 63 not containing an N-terminal transactivation domain; VIM, vimentin. 
Table 2 Real-Time RT-PCR Primers

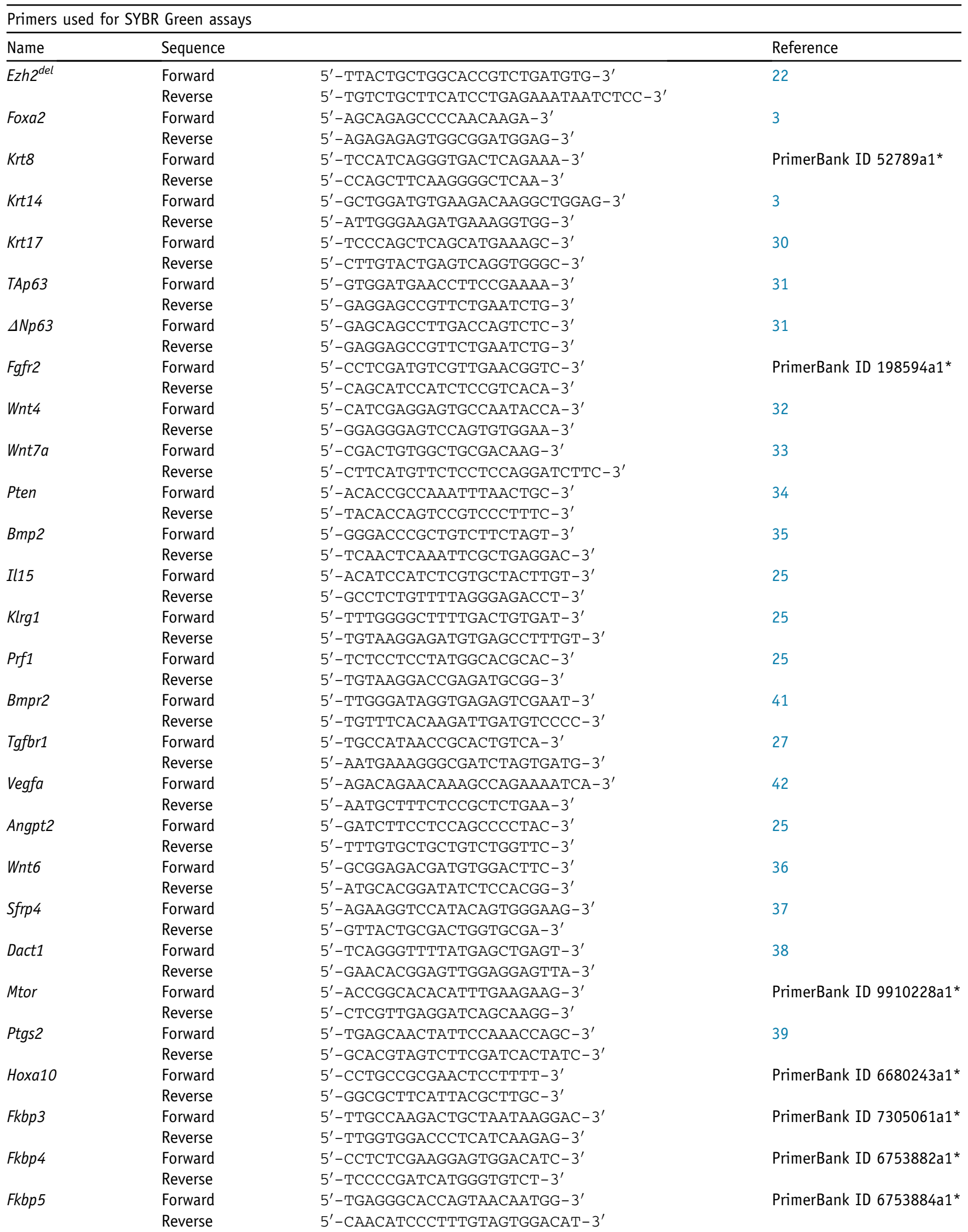

(table continues) 
Table 2 (continued)

\begin{tabular}{|c|c|c|c|}
\hline \multicolumn{4}{|c|}{ Primers used for SYBR Green assays } \\
\hline Name & Sequence & & Reference \\
\hline Rpl19 & Forward & $5^{\prime}-$ ATGAGTATGCTCAGGCTACAGA-3' & 29 \\
\hline \multicolumn{4}{|c|}{ TaqMan gene expression assay } \\
\hline \multicolumn{2}{|l|}{ Name } & ID & Manufacturer \\
\hline \multicolumn{2}{|l|}{ Prl8a2 } & Mm01135453_m1 & Thermo Fisher Scientific \\
\hline \multicolumn{2}{|l|}{ Corin } & Mm00444120_m1 & Thermo Fisher Scientific \\
\hline \multicolumn{2}{|l|}{ Rpl19 } & Mm02601633_g1 & Thermo Fisher Scientific \\
\hline
\end{tabular}

${ }^{*}$ Accessible at https://pga.mgh.harvard.edu/primerbank.

ID, identification.

antigen, followed by incubation with $3 \% \mathrm{H}_{2} \mathrm{O}_{2}$ solution for 10 minutes. Inactivation of endogenous peroxidase activity was only performed for the immunohistochemical procedure. Sections were blocked before incubation with primary antibodies (Table 1 ) overnight at $4^{\circ} \mathrm{C}$. After primary antibody incubation, the avidin-biotin complex kit (catalog number PK-6100; Vector Laboratories, Burlingame, CA) was used, with NovaRed (catalog number SK-4800; Vector Laboratories) being the developing substrate (for immunohistochemistry). Sections were mounted using mounting media [catalog number 17986-01 (Thermo Fisher Scientific, Waltham, MA) or catalog number 3801743 (Leica Biosystems, Buffalo Grove, IL)]. For immunofluorescence microscopy, sections were mounted using medium that contains DAPI, a nuclear counterstain (catalog number P36931; Thermo Fisher Scientific).

\section{Dolichos Biflorus Agglutinin Lectin Staining}

Dolichos biflorus agglutinin staining was performed, as detailed elsewhere, with slight modifications. ${ }^{28}$ After deparaffinization and rehydration, sections were boiled in citrate buffer ( $\mathrm{pH} 6$ ) for 20 minutes, blocked with $5 \%$ bovine serum albumin in Tris-buffered saline for 30 minutes, and incubated with fluorescein-labeled dolichos biflorus agglutinin (catalog number FL-1031; Vector Laboratories), that was diluted $1: 100$ in $1 \%$ bovine serum albumin/Tris-buffered saline overnight at $4^{\circ} \mathrm{C}$. Sections were mounted with DAPIcontaining medium described above.

\section{Western Blot Analysis}

Uterine protein samples were prepared, and Western blot analysis was conducted, as previously described. ${ }^{26}$ Information for primary antibodies is listed in Table 1. Chemiluminescent substrate (catalog number WBKLS0100; Millipore Sigma) was used for signal detection. Digital images were captured using the ChemiDoc imaging system
(Bio-Rad, Hercules, CA) and processed using Adobe Photoshop CS5 (Adobe Inc., San Jose, CA).

\section{Quantitative RT-PCR}

RNA isolation and quantitative RT-PCR were conducted as described. ${ }^{29}$ Reverse transcription was performed using $500 \mathrm{ng}$ (for uterine or decidual tissues) or $200 \mathrm{ng}$ (for uterine epithelium) of total RNA and Superscript III Reverse Transcriptase (catalog number 18080044; Thermo Fisher Scientific). Quantitative PCR was performed in duplicate using either SYBR Green (catalog number 1725121; Bio-Rad) or TaqMan Mix (catalog number 4304437; Thermo Fisher Scientific). The sequences of gene-specific primers ${ }^{3,22,25,27,29-42}$ and information on TaqMan probes are listed in Table 2. The average $\mathrm{C}_{\mathrm{T}}$ value for each gene was normalized to that of ribosomal protein L19 (Rpl19), and relative gene expression levels were calculated as described. ${ }^{43}$

\section{Statistical Analysis}

The statistical difference between two groups was examined using the unpaired two-tailed $t$-test. Data are given as means \pm SEM. $P<0.05$ denotes statistical significance.

\section{Results}

\section{Conditional Ablation of EZH2 in the Uterus}

Expression of EZH2 has been reported in the glandular epithelium and stroma of the human uterus. ${ }^{16}$ To verify the expression of EZH2 in the mouse uterus, immunohistochemistry was performed using an antibody directed to EZH2. The results showed strong immunoreactive signals of EZH2 in both luminal and glandular epithelia of the mouse uterus (Supplemental Figure S1). Lower levels of EZH2 were detected in the myometrium (Supplemental Figure S1). 
Immunostaining for EZH2 in the stroma appeared to be variable during the estrous cycle (Supplemental Figure S1).

EZH2 is involved in epithelial-mesenchymal transition in cancer cells. ${ }^{44}$ To determine whether EZH2 is required for uterine epithelial integrity, uterine $E z h 2$ was deleted using $\mathrm{Pgr}$-Cre that is expressed in both epithelial and mesenchyme-derived cells of the uterus. ${ }^{21}$ Figure $1 \mathrm{~A}$ depicts the conditional allele of $E z h 2$ in which exons 14 and 15 are flanked by two locus of X-over of P1 (LoxP) sites. ${ }^{22}$ Cremediated deletion of the target exons is expected to cause a frameshift mutation that eliminates the SET domain. ${ }^{22}$ As anticipated, deletion of $E z h 2$ was evidenced by the presence of a recombined Ezh2 allele in the Ezh2 cKO uterus (Figure 1, A and B). Consistent with this, real-time PCR detected a significant reduction of $E z h 2$, but not Ezhl, mRNA levels in 1-month-old Ezh2 cKO mice (Figure 1C), confirming Ezh2-specific deletion in the uterus. Ablation of EZH2 was further verified by Western blot analysis (Figure 1D) and immunohistochemical analyses using uteri from 2-month-old mice (Figure 1, E and F). Thus, EZH2 was efficiently depleted in the uterus.

\section{Depletion of EZH2 Leads to the Formation of Stratified Uterine Epithelium}

To determine the potential impact of EZH2 depletion on uterine development, we examined the morphology of the uterus at 1 month of age. The uterus was histologically normal, consisting of major structural components, including the myometrium and endometrium, revealed by hematoxylin and eosin staining (Figure 2, A-D). It is well established that cytokeratin 8 (KRT8) is expressed in simple epithelia, whereas KRT5, KRT6, and KRT14 are produced by stratified epithelia. ${ }^{45}$ Immunostaining of KRT8 showed the presence of both luminal and glandular epithelium within the endometrium (Supplemental Figure S2, A and D). Both Ezh2 cKO and control uteri expressed stromal cell marker vimentin (Supplemental Figure S2, B and E). The myometrium of $E z h 2$ cKO mice appeared to be indistinguishable from that of controls by immunostaining of $\alpha$-smooth muscle actin (Supplemental Figure S2, C and F). However, further immunohistochemical analysis of the uterus, using antibodies directed to basal cell markers KRT14 and tumor protein 63 (p63), demonstrated focal expression of these proteins in a cell layer beneath luminal and/or glandular epithelial cells in $E z h 2$ cKO uteri (Figure 2, H-J), which is in sharp contrast to normal controls (Figure 2, E-G).

Similar epithelial abnormalities in limited regions were found in the uteri of 2-month-old $E z h 2 \mathrm{cKO}$ mice (Figure 3, $\mathrm{A}$ and B) compared with controls (Figure 3C). At approximately 8 months of age, epithelial stratification was escalated in Ezh2 cKO mice. This was evidenced by the presence of cells positively stained for KRT14 (Figure 3, D and E), KRT5 (Figure 3, G and H), KRT6A (Figure 3, J and K), and p63 (Figure 3, M and $\mathrm{N}$ ) in the uteri of Ezh2 cKO mice. Agematched controls were included (Figure 3, F, I, L, and O). The development of stratified epithelia was accompanied by endometrial hyperplasia, evident in nulliparous $E z h 2 \mathrm{cKO}$ mice at the age of 5 to 8 months (Figure 3 and Supplemental Figure S3). Histologically, cystic dilation of endometrial glands containing eosin-stained substance could be observed in Ezh2 cKO uteri (Supplemental Figure S3, B and C), compared with controls (Supplemental Figure S3A). The morphologically altered glands were variable in size, and some of them contained stratified epithelial layers (Figure 3, D, E, G, H, J, K, M, and N, and Supplemental Figure S3, B and C), with nuclear atypia in some cases (Figure 3, E and H, and Supplemental Figure S3, C and D). A minor level of gland crowding was observed in discrete regions of $E z h 2 \mathrm{cKO}$ uteri, in which intervening stroma among glands was sparse (Supplemental Figure S3, B and D). Immunostaining of vimentin that marks uterine stroma confirmed this observation (Supplemental Figure S3, E and F). Despite the pathologic changes in the endometrium, the myometrial layers remained intact in $E z h 2 \mathrm{cKO}$ mice (Supplemental Figure S3B). Moreover, immunoreactive signals for $\mathrm{Ki}-67$ could be detected in some abnormal glands or cystic glandular structures in $E z h 2$ cKO uteri (Supplemental Figure S3, G-L). The weight of uterine horns from $E z h 2 \mathrm{cKO}$ mice $(28.8 \pm 5.6 \mathrm{mg} ; n=3)$ was increased compared with controls $(11.7 \pm 1.1 \mathrm{mg}$; $n=6$ ), even before sexual maturity ( 1 month; $P<0.01$ ). Collectively, the endometrial pathology in Ezh2 cKO mice resembled human endometrial hyperplasia. ${ }^{46,47}$

To determine whether the observed epithelial abnormalities in the EZH2-ablated uterus were associated with dysregulation of genes known to regulate uterine epithelial stratification, the transcript levels of $\mathrm{Fg} f \mathrm{r} 2{ }^{3}$, wingless-type MMTV integration site family member 4 (Wnt4), Wnt $7 a{ }^{49}$ and phosphatase and tensin homolog (Pten $)^{50}$ were examined using both uterine tissues and isolated uterine epithelia from $E z h 2$ cKO mice. Significant differences were not detected in the expression of these genes in uterine tissues or epithelial preparations between control and Ezh2 cKO mice (Supplemental Figure S4).

\section{Altered FOXA2 Expression in EZH2-Depleted Uterus}

A recent study has shown that altered expression of FOXA2 is associated with epithelial stratification. ${ }^{51}$ Therefore, it was determined if dysregulation of FOXA2 contributed to the formation of stratified epithelia in $E z h 2$ cKO uteri. At 2 months of age, glandular epithelia were identified by FOXA2 staining in control uteri (Figure 4, A and B). However, partial loss of FOXA2 immunostaining was observed in the glandular epithelia of $E z h 2 \mathrm{cKO}$ mice (Figure 4, C-F). This result agrees with the finding that Foxa 2 mRNA levels were decreased in uterine epithelia of $E z h 2 \mathrm{cKO}$ mice at 1 month of age (Figure 4G). In addition, double immunofluorescence staining of KRT14 and FOXA2 showed no FOXA2 expression in KRT14-positive epithelial cells lining the luminal/glandular epithelia of Ezh2 cKO uteri (Figure 5, B, $\mathrm{D}$, and F), in contrast to controls lacking specific KRT14 


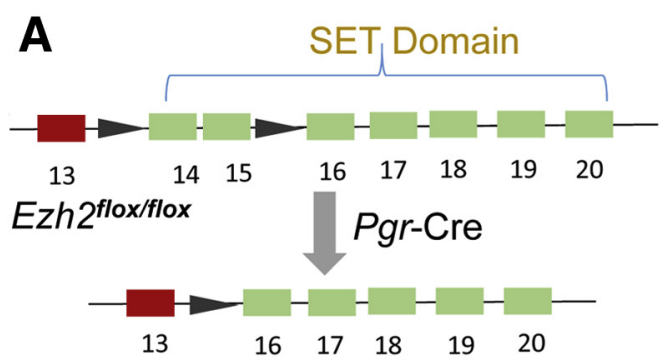

D

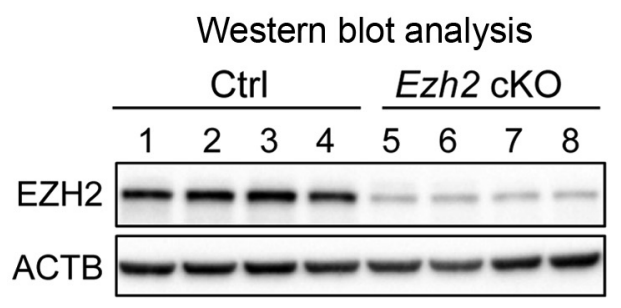

B

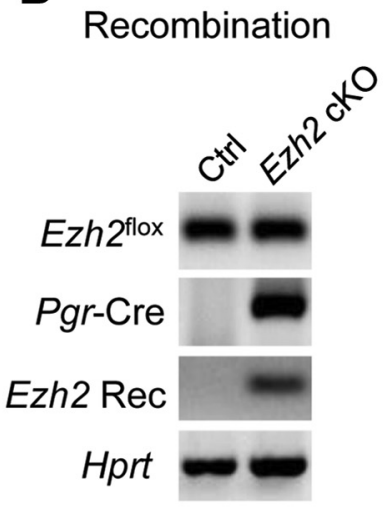

E

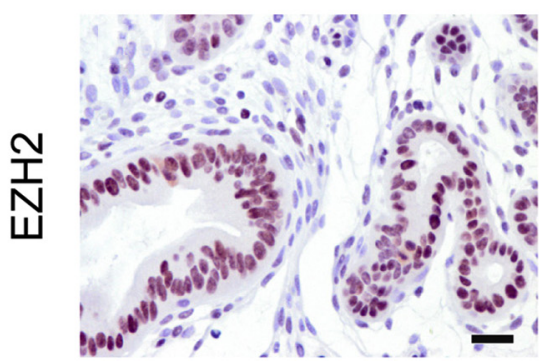

C

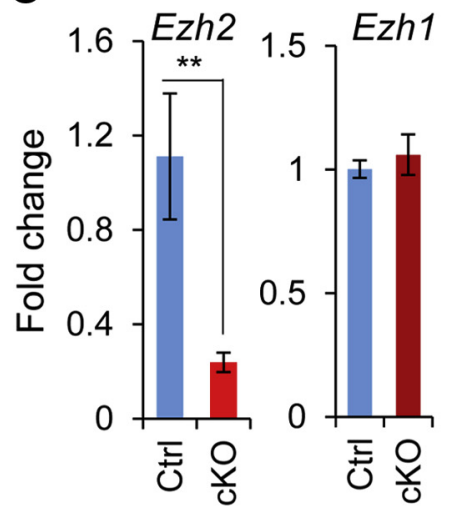

$\mathbf{F}$

Figure 1 Conditional deletion of Ezh2 in the mouse uterus. A: Schematic representation of Pgr-Cre-mediated inactivation of Ezh2 floxed allele. B: Recombination of Ezh2 conditional allele in Ezh2 cK0 uteri. The Ezh2 recombined allele (Ezh2 Rec) was only detectable in the uterus of the Ezh2 cK0 mouse but not the control (Ctrl). C: Reduction of Ezh2, but not Ezh1, mRNA levels in the uteri of 1-month-old Ezh2 cK0 mice versus controls. D: Western blot analysis of EZH2 protein levels in control and Ezh2 cKO mice. Each lane represents an independent uterine sample from a 2-month-old mouse. $\beta$-Actin (ACTB) was included as an internal control. E and F: Immunohistochemical staining of EZH2 in the uteri of 2-month-old control and Ezh2 cKO mice. Three independent samples per group were examined. Note the diminished immunoreactive signals in the epithelia of Ezh2 cKO uteri (F) compared with controls (E). Data are expressed as means \pm SEM (C). $n=4$ Ctrl mice (C and D); $n=5$ cK0 mice (C); $n=4$ cKO mice (D). ${ }^{* * P}<0.01$. Scale bars $=20 \mu \mathrm{m}(\mathbf{E}$ and $\mathbf{F})$.

staining (Figure 5, A, C, and E). Negative controls are shown in Figure 5, G and $\mathrm{H}$. Because FOXA2 regulates the expression of genes involved in uterine gland development and function, ${ }^{52}$ these results suggest that conditional deletion of Ezh2 may impair uterine function.

\section{Conditional Deletion of EZH2 in the Mouse Uterus Produces Basal-Like Epithelial Cells Expressing Genes Associated with the Basal Cell Phenotype}

Double indirect immunofluorescence of KRT8 and KRT14 demonstrated the presence of basal-like epithelial cells (KRT14 positive but KRT8 negative) lining some KRT8-positive epithelial cells in the uteri of $E z h 2 \mathrm{cKO}$ mice (Figure 6, $\mathrm{E}-\mathrm{H}$ ), in contrast to the controls in which epithelia were only stained for KRT8 (Figure 6, A-D). To understand the molecular underpinnings of the observed basal-like cell phenotype, it was examined whether ablation of EZH2 promoted the expression of basal cell-related genes, including $\mathrm{Krt5}$, Krt14, Krt17, and TAp63 and $\triangle N p 63$ [containing an N-terminal transactivation (TA) domain and not containing this domain, respectively], that encode p63 isoforms using 1-month-old mice. Results showed that transcript levels of $\mathrm{Krt5}, \mathrm{Krt14}$, and $K r t 17$ were significantly elevated in $E z h 2$ cKO uteri compared with those in age-matched controls (Figure 6, I-K). In contrast,
mRNA levels of $K r t 8$ were not significantly altered between $E z h 2 \mathrm{cKO}$ and control uteri (Figure $6 \mathrm{~L}$ ). Interestingly, the mRNA expression of $\triangle N p 63$, but not $T A p 63$, was dramatically increased in the uteri of $E z h 2 \mathrm{cKO}$ mice (Figure 6, M and N). To further demonstrate dysregulation of basal cell-related genes in the epithelial compartment, uterine epithelia were isolated from both control and $E z h 2 \mathrm{cKO}$ uteri at 1 month of age and real-time PCR analysis was performed. In line with results obtained using uterine tissues, increased expression of $\Delta N p 63, \mathrm{Krt5}$, and $\mathrm{Krt} 14$ was found in uterine epithelia of $E z h 2 \mathrm{cKO}$ mice compared with controls (Supplemental Figure S5). Thus, loss of EZH2 produces basal-like epithelial cells or a cell population expressing basal markers.

\section{Ablation of EZH2 Impairs Female Fertility}

To examine whether EZH2 depletion in the uterus impacts female fertility, $E z h 2 \mathrm{cKO}$ mice and controls were continuously mated with fertile male mice for a period of 6 months. During the fertility test, $E z h 2 \mathrm{cKO}$ mice showed a reduced number of litters and a smaller litter size compared with controls (Figure 7, A and B). Although all control mice delivered normally, approximately $64 \%$ of $E z h 2 \mathrm{cKO}$ mice exhibited signs of dystocia or difficulty in labor during the testing period. Histologic analysis of the ovary showed 


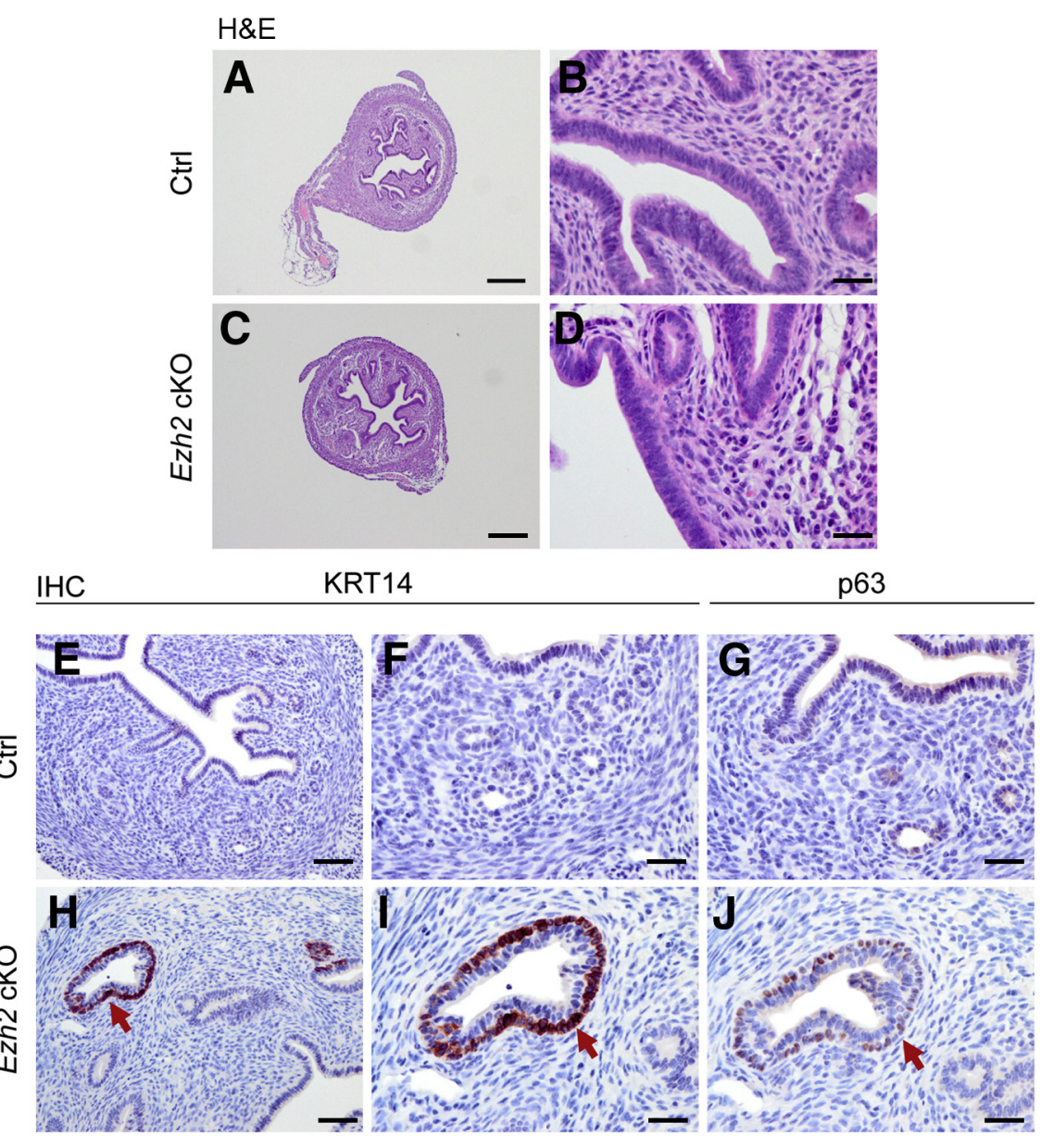

Figure 2 Ablation of EZH2 results in focal formation of stratified uterine epithelium. A-D: Hematoxylin and eosin staining of uterine samples from 1-month-old control (Ctrl) and Ezh2 cKO mice. A-D: Higher-magnification images (B and D) for $\mathbf{A}$ and $\mathbf{C}$, respectively. $\mathbf{E}-\mathbf{J}$ : Immunostaining of cytokeratin 14 (KRT14) and tumor protein 63 (p63) using 1-month-old control and Ezh2 cKO uteri. Note the immunoreactive signals of KRT14 beneath the epithelial layer of a uterine gland and the p63-specific signals in the same gland on an adjacent section (arrows). E, F, H, and I: Highermagnification images ( $\mathbf{F}$ and $\mathbf{I}$ ) for $\mathbf{E}$ and $\mathbf{H}$, respectively. Three independent samples per group were examined. Scale bars: $250 \mu \mathrm{m}$ (A and $\mathbf{C}) ; 25$ $\mu \mathrm{m}$ (B, D, F, G, I, and J); $50 \mu \mathrm{m}$ (E and $\mathbf{H})$. Original magnification: $\times 40(\mathbf{A}$ and $\mathbf{C}) ; \times 400(\mathbf{B}$, D, F, G, I, and J); $\times 200$ (E and H). H\&E, hematoxylin and eosin staining; IHC, immunohistochemistry.

normal follicular development in $E z h 2 \mathrm{cKO}$ mice (Figure 7, $\mathrm{C}$ and D). Furthermore, blastocysts could be retrieved from $E z h 2$ cKO uteri at embryonic day 3.5 (E3.5; data not shown). Our findings indicate that the reduced reproductive potential of $E z h 2 \mathrm{cKO}$ mice is likely caused by impaired uterine function.

To explore the potential effect of $E z h 2$ deletion on uterine decidual function, it was first verified that $E z h 2$ expression was reduced in $\mathrm{E} 8.5$ decidual tissues collected from $E z h 2 \mathrm{cKO}$ mice (Figure 7E). Implantation sites could be found in $E z h 2 \mathrm{cKO}$ mice at E8.5 (Supplemental Figure S6A), suggesting that decidualization occurred in these mice. Further analysis revealed potential defects in decidual differentiation, evidenced by impaired expression of prolactin family 8 subfamily a member 2 (Prl8a2), a decidual marker, in $E z h 2$ cKO decidual tissues (Figure 7E). However, mRNA expression of another key regulator of decidualization, bone morphogenetic protein 2 (Bmp2), was not significantly altered (Figure 7E). The analysis was extended to additional genes involved in decidualization, including Wnt4, Wnt6, secreted frizzled-related protein 4 (Sfrp4), disheveled-binding antagonist of $\beta$-catenin 1 (Dact1), mechanistic target of rapamycin kinase (Mtor; alias Frapl), prostaglandin-endoperoxide synthase 2 (Ptgs2), homeobox A10 (Hoxa10), and FK-506-binding protein 3 (Fkbp3),
Fkbp4, and Fkbp5..$^{48,53-55}$ None of these genes was significantly altered, except $F k b p 4$, which was up-regulated in $E z h 2 \mathrm{cKO}$ uteri (Supplemental Figure S6B). Because decidualization is accompanied by active angiogenesis and vascular remodeling, ${ }^{56,57}$ the expression of angiogenic factors, including vascular endothelial growth factor A (Vegfa), angiopoietins (Angpts) 1,2, and 4, and Corin, a gene critical for uterine spiral artery remodeling, was next examined. ${ }^{58}$ The transcript levels of Angpt2 and Corin were significantly reduced in E8.5 deciduae from $E z h 2 \mathrm{cKO}$ mice (Figure 7E). Interestingly, dysregulation of genes associated with the recruitment/differentiation of uterine natural killer cells, including IL-15 (Il-15), killer cell lectin-like receptor subfamily G member 1 (Klrgl), and perforin 1 (Prfl), was also found (Figure 7E). Dolichos biflorus agglutinin lectin staining showed that the number of uterine natural killer cells was reduced in E8.5 decidual basalis of Ezh2 cKO mice versus controls (Figure 7, F-I). Because defects in uterine natural killer cell recruitment/differentiation were found in mice with conditional deletion of BMP receptor 2 (BMPR2) or transforming growth factor- $\beta$ receptor 1 (TGFBR1), ${ }^{25,59}$ the expression of both genes was examined in the deciduae of $E z h 2$ cKO mice. Results showed comparable expression levels of Bmpr2 and Tgfbrl mRNA in decidual tissues between $E z h 2$ 


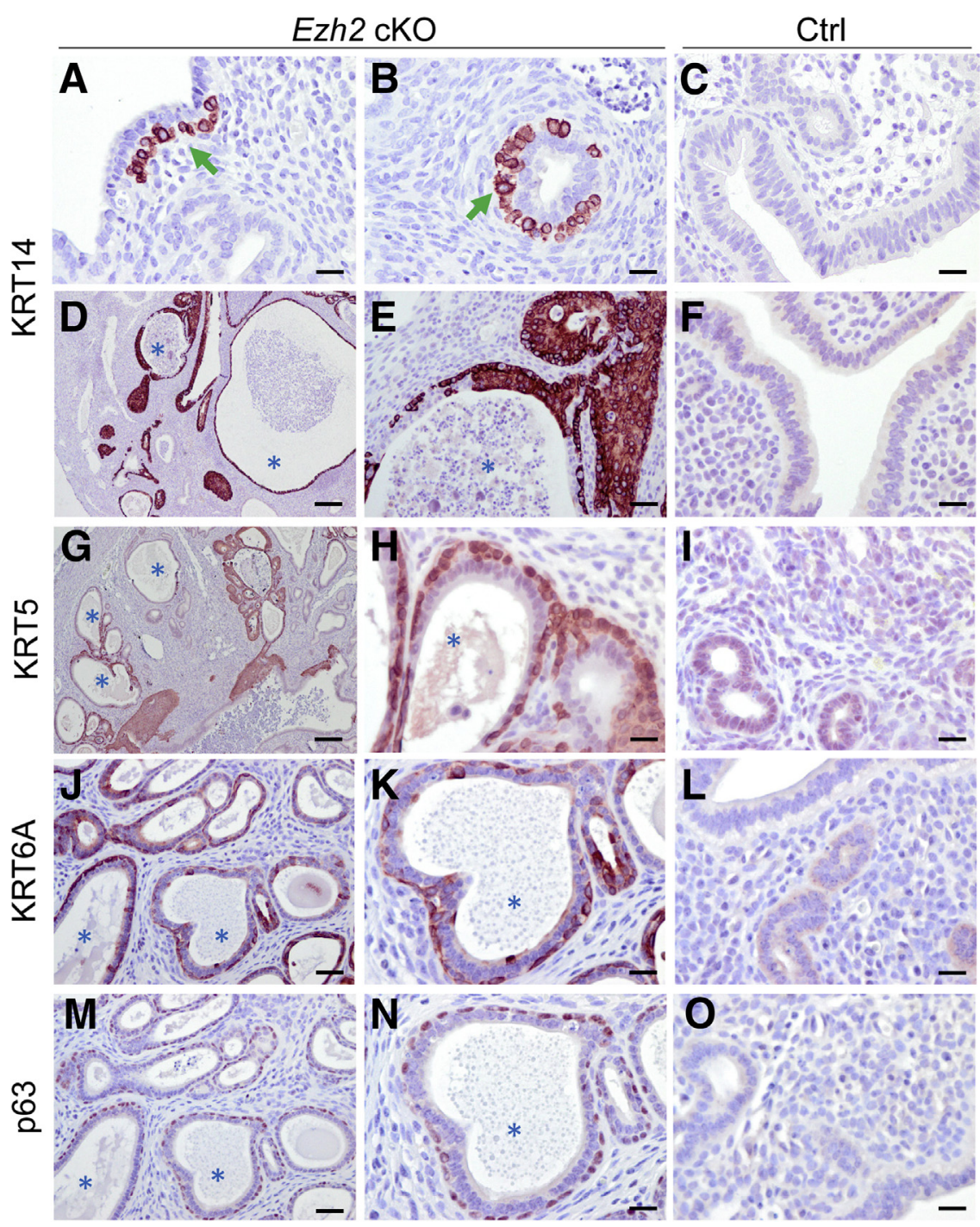

Figure 3 Epithelial stratification and endometrial hyperplasia in aged Ezh2 cKO mice. A-F: Expression of cytokeratin 14 (KRT14) in the uteri from control (Ctrl) and Ezh2 cKO mice at 2 (A-C) and 8 (D-F) months of age. More extensive immunoreactive signals of KRT14 were found in the uteri of 8-month-old mice ( $\mathbf{D}$ and $\mathbf{E}$ ) versus 2month-old mice (A and $\mathbf{B}$ ). Panel $\mathbf{E}$ shows a higher-magnification image of $\mathbf{D}$. Arrows indicate KRT14-positive cells. G-0: Expression of KRT5, KRT6A, and tumor protein 63 (p63) in 8-month -old Ezh2 cKO and control mice. G, H, J, K, M, and $\mathbf{N}$ : Higher-magnification images $(\mathbf{H}, \mathbf{K}$, and $\mathbf{N})$ for $\mathbf{G}, \mathbf{J}$, and $\mathbf{M}$, respectively. $\mathbf{J}, \mathbf{K}, \mathbf{M}$, and $\mathbf{N}$ : Adjacent sections ( $\mathbf{M}$ and $\mathbf{N}$ ) for $\mathbf{J}$ and $\mathbf{K}$, respectively. At least three independent samples per group were examined. Asterisks indicate cyst-like structures. Scale bars: $20 \mu \mathrm{m}(\mathbf{A}-\mathbf{C}, \mathbf{F}, \mathbf{H}, \mathbf{I}, \mathbf{K}, \mathbf{L}$, $\mathbf{N}$, and $\mathbf{0}) ; 40 \mu \mathrm{m}(\mathbf{E}, \mathbf{J}$, and $\mathbf{M}) ; 200 \mu \mathrm{m}$ (D and $\mathbf{G})$.

cKO mice and controls (Figure 7E), suggesting that EZH2 may act independently or upstream/downstream of BMPR2 and TGFBR1. The findings of dysregulation of genes involved in angiogenesis and vascular remodeling, together with the observed reduction of the number of uterine natural killer cells in Ezh2 cKO mice, indicate potentially impaired decidual function during pregnancy.

\section{Discussion}

Numerous reports highlight the involvement of EZH2 in multiple stages of cancer development, including initiation, formation, progression, and metastasis. ${ }^{60}$ As a core member of the PRC2 group, EZH2 promotes the proliferation and invasion of endometrial carcinoma, ${ }^{61}$ drives epithelial-mesenchymal transition in endometriosis, ${ }^{62}$ and hampers the expression of DNA damage repair genes in uterine fibroids. ${ }^{15}$ In contrast, the physiological function of EZH2 in the uterus remains largely unknown. One study using in vitro cultured human endometrial stromal cells indicates that decidualization is accompanied by a down-regulation of EZH2 expression to allow for epigenetic programming. ${ }^{16}$ Treatment of mice with DNA demethylating agent, 5-aza- $2^{\prime}$-deoxycytidine, impairs embryo implantation. ${ }^{63}$ These studies indicate that modifications of chromatin and DNA are important for normal uterine function. Global deletion of $E z h 2$ leads to embryonic lethality during early development, ${ }^{64}$ precluding further characterization of the function of EZH2 during postnatal uterine development. This issue was circumvented by using the Cre-LoxP approach to delete $E z h 2$ in the uterus. EZH2 seems to play important roles in maintaining endometrial homeostasis and integrity.

The inner surface of the uterus is lined by a single layer of simple columnar epithelial cells, which extend into the endometrium to form uterine glands. Stratification of uterine epithelial cells is a pathologic event and has been observed in several genetically modified mouse models described below. Conditional deletion of $F g f r 2$ in the mouse uterus leads to the formation of stratified luminal epithelium, with the occurrence of p63 and KRT14-positive basal cells. ${ }^{3}$ Despite the normal 


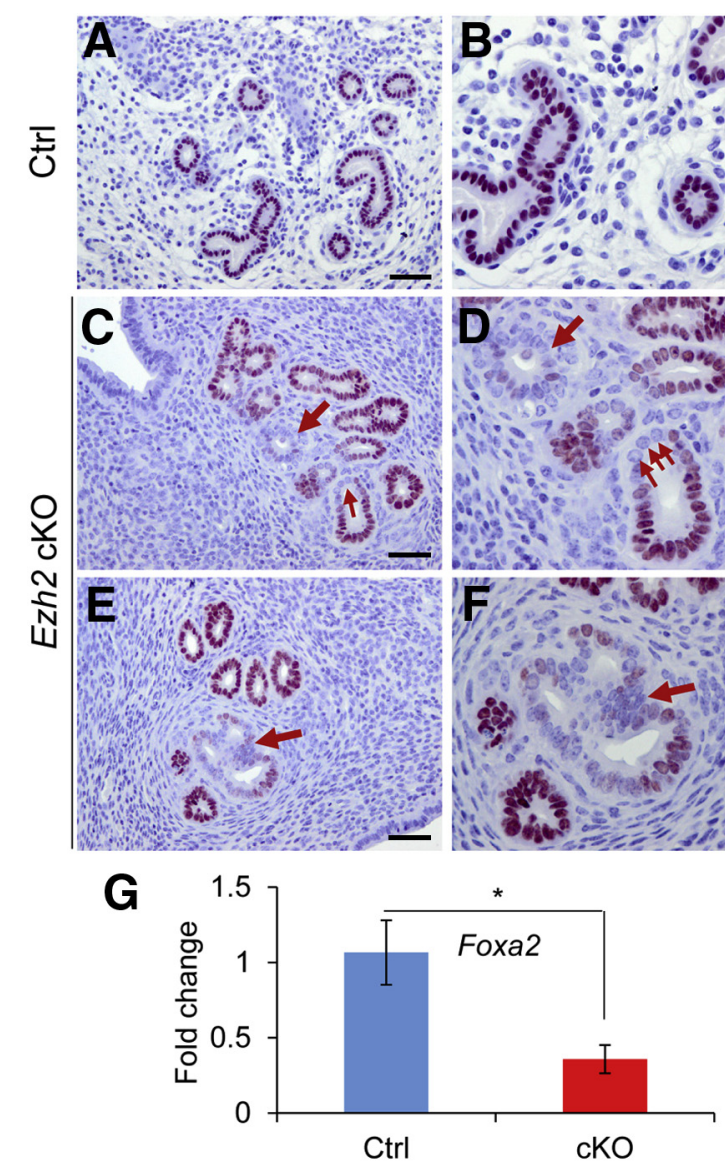

Figure 4 Dysregulation of forkhead box A2 (FOXA2) in the uteri of Ezh2 CK0 mice. A-F: Immunohistochemical analysis of FOXA2 distribution in the uteri of control (Ctrl) and Ezh2 cKO mice at the age of 2 months. A, C, and $\mathbf{E}$ are shown at higher magnification in $\mathbf{B}, \mathbf{D}$, and $\mathbf{F}$, respectively. Note the reduction or partial loss of FOXA2 signals in some uterine glands of Ezh2 cK0 mice versus controls (arrows). Three independent samples per group were examined. G: Real-time PCR analysis of expression of Foxa2 mRNA in uterine epithelia isolated from control and Ezh2 CKO mice. Data are expressed as means \pm SEM (G). $n=4(\mathbf{G}) .{ }^{*} P<0.05$. Scale bars: $50 \mu \mathrm{m}$ $(\mathbf{A}, \mathbf{C}$, and $\mathbf{E}) ; 25 \mu \mathrm{m}(\mathbf{B}, \mathbf{D}$, and F). Original magnification: $\times 200(\mathbf{A}, \mathbf{C}$, and E); $\times 400($ B, D, and F).

appearance of uterine stromal cells and the myometrial layer, these mice show fertility defects due to pregnancy loss during the peri-implantation period. ${ }^{3}$ Loss of PTEN in the mouse uterus, using $P g r$-Cre, promotes tumorigenesis, epithelial stratification, and squamous differentiation, characterized by the presence of KRT5- and p63-positive epithelial cells. ${ }^{50}$ In contrast, deletion of Pten, specifically in the epithelium using lactoferrin-Cre, does not cause stratification but results in apoptosis of epithelial cells, suggesting a potential role of PTEN-mediated epithelial-mesenchymal communication in epithelial stratification. ${ }^{50}$ Dysregulation of the WNT pathway is also associated with epithelial stratification. Deletion of Wnt4 in the mouse uterus causes the formation of stratified luminal epithelium and glandular defects, accompanied by defective embryo implantation and stromal cell function. ${ }^{48}$ Wnt7a-null mice also show stratified epithelium and defective adenogenesis in the uterus. ${ }^{49}$ Interestingly, conditional deletion of
Wnt7a in the mouse uterus postnatally does not induce stratification of uterine epithelium, suggesting that the timing of WNT7A loss may contribute to the phenotypic difference observed between the ubiquitous deletion and conditional knockout models. ${ }^{65}$ Further supporting the role of the WNT pathway in maintaining epithelial integrity, dysregulation of beta catenin induces epithelial stratification. ${ }^{66}$ Recently, it was shown that conditional overexpression of FOXA2 in the mouse uterus results in the development of stratified luminal/glandular epithelium. ${ }^{51}$ In the stratified luminal epithelium of adult transgenic mice, FOXA2 was expressed in the nuclei of cells within the upper nonbasal layer. ${ }^{51}$ These results indicate that dysregulation of FOXA2 may cause epithelial stratification. ${ }^{51}$ The observation that decreased FOXA2 expression in the uteri of adult $E z h 2 \mathrm{cKO}$ females was not accompanied by depletion of uterine glands suggests a stage-specific function of FOXA2 in uterine gland development. Indeed, a recent study showed that adenogenic defects in Foxa 2 conditional knockout mice are dependent on the stage of FOXA2 depletion; and ablation of FOXA2 in the uteri of adult mice does not affect uterine

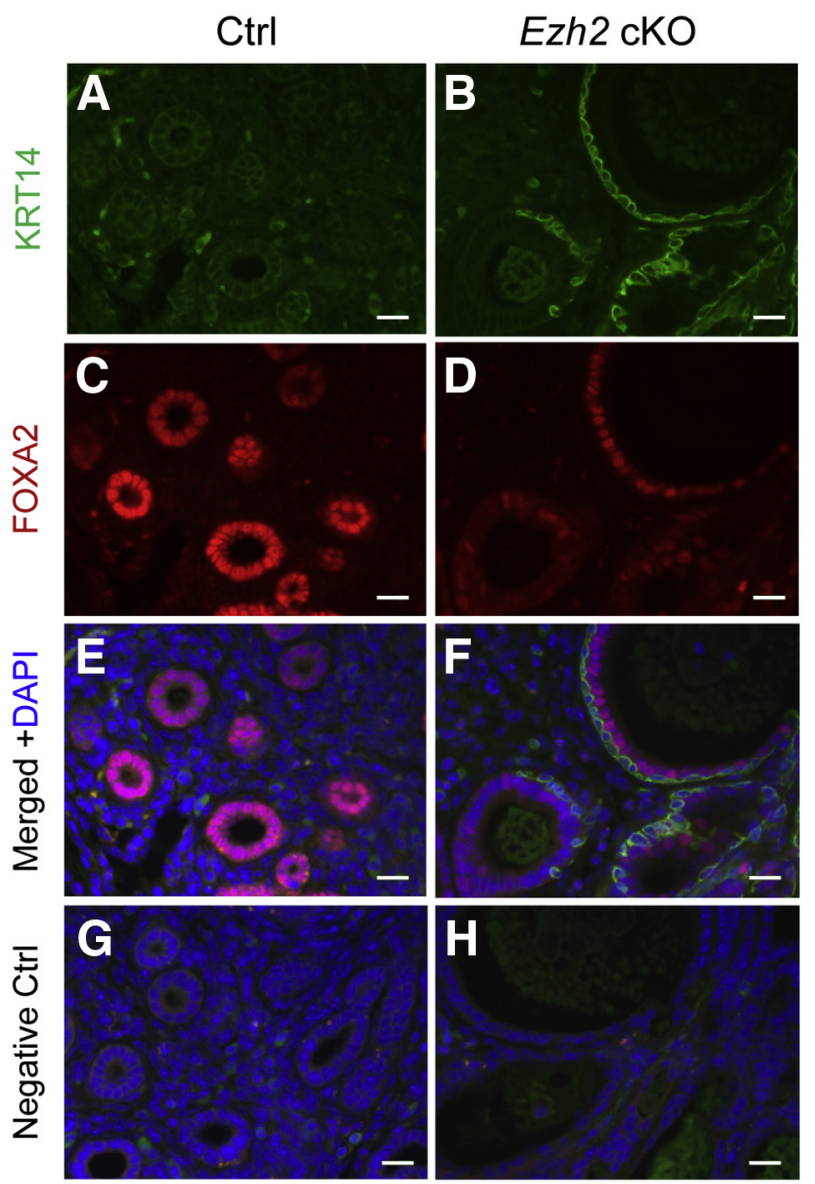

Figure 5 Minimal forkhead box A2 (FOXA2) expression in cytokeratin 14 (KRT14)-positive cells. A-F: Double-immunofluorescence staining of KRT14 and FOXA2 in the uteri of control (Ctrl; A, C, and E) and Ezh2 cKO (B, $\mathbf{D}$, and $\mathbf{F}$ ) mice at the age of 8 months. KRT14-positive cells (green) did not express FOXA2 (red). G and H: Negative controls, using isotype-matched IgGs to replace primary antibodies, are shown. At least three independent samples per group were examined. Scale bars $=20 \mu \mathrm{m}(\mathbf{A}-\mathbf{H})$. 

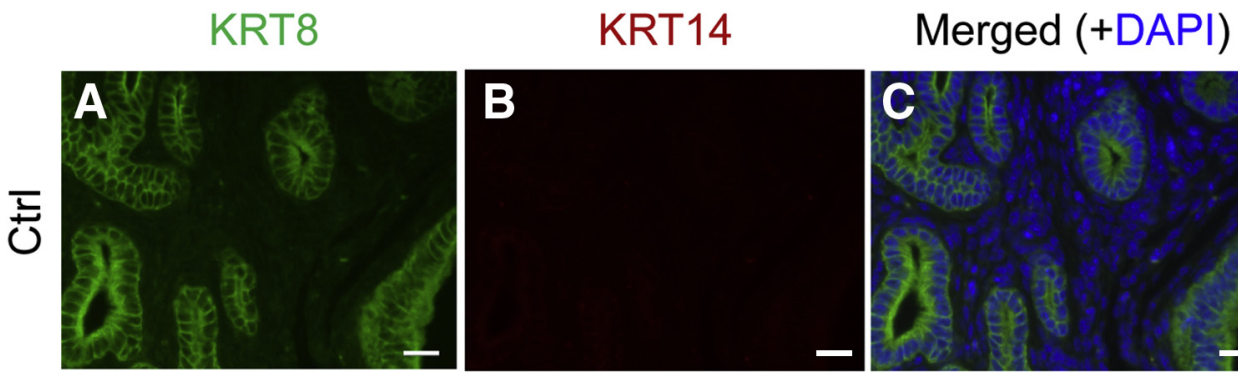

\section{Negative Ctrl}
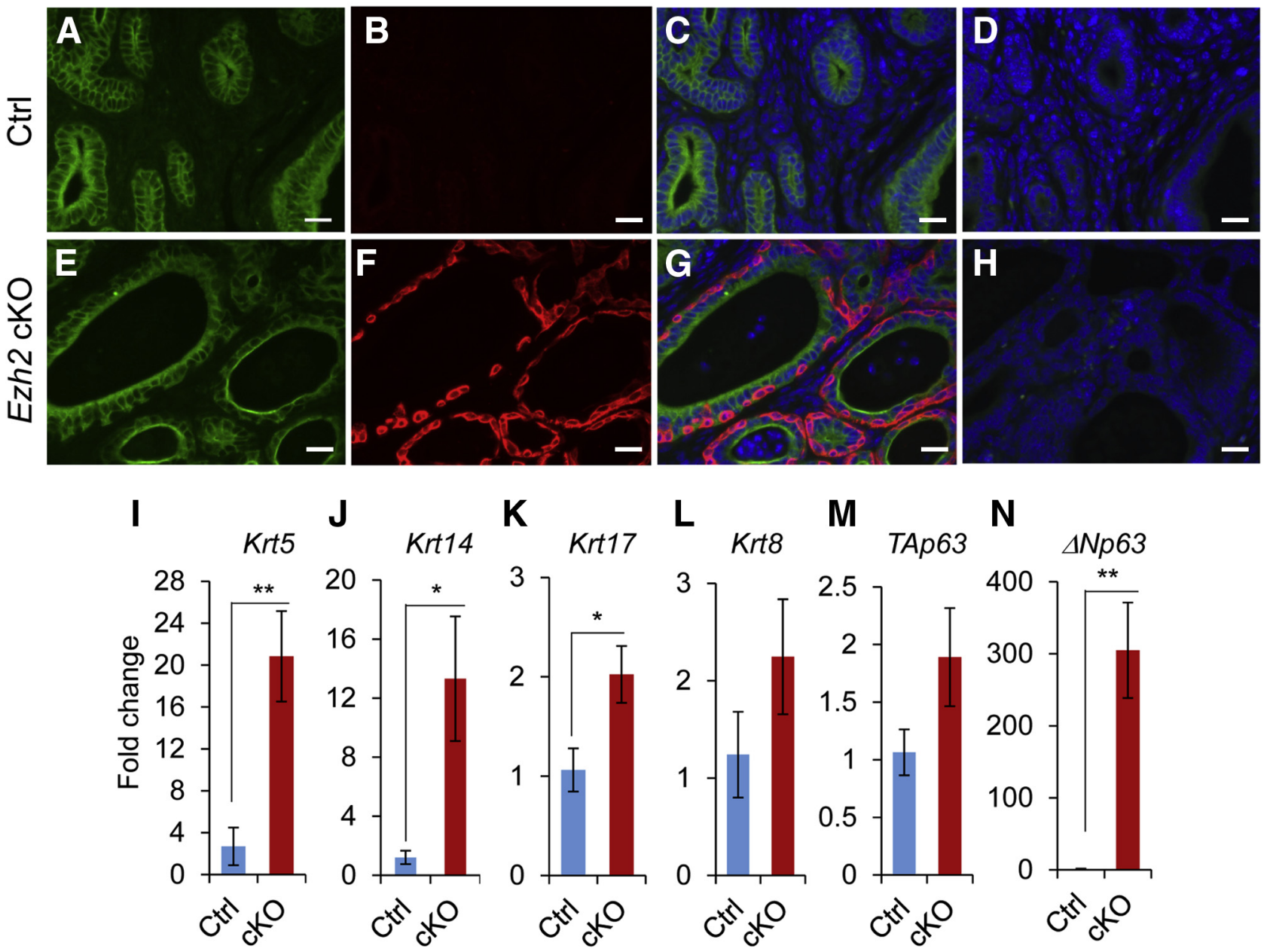

Figure 6 Ablation of EZH2 produces basal-like cell types with up-regulation of basal cell makers. A-H: Double-immunofluorescence staining of cytokeratin 8 (KRT8) and KRT14 in the uteri of control (Ctrl; A-D) and Ezh2 cKO (E-H) mice at the age of 8 months. D and H: Negative controls using IgGs are shown. At least three independent samples per group were examined. I-N: Real-time PCR analysis of Krt5, Krt14, Krt17, Krt8, TAp63, and $\triangle N p 63$ transcript levels in the uteri of control and Ezh2 cK0 mice at the age of 1 month. Data are expressed as means \pm SEM (I-N). $n=4$ (I-N, Ctrl mice); $n=5$ (I-N, cKO mice). ${ }^{*} P<0.05,{ }^{* *} P<0.01$. Scale bars $=20 \mu \mathrm{m}(\mathbf{A}-\mathbf{H})$.

gland formation. ${ }^{8}$ As FOXA2 is a key regulator of the function of uterine glands, ${ }^{8}$ reduced FOXA2 expression in Ezh2 cKO mice likely leads to impaired glandular function.

Despite these findings, little is known about how dysregulation of the aforementioned genes leads to epithelial stratification. Our results did not reveal a direct link between EZH2 and dysregulation of Fgfr2, Wnt4, Wnt7a, and Pten in the formation of stratified uterine epithelium. Instead, our data suggest that $\mathrm{EZH} 2$ is required for uterine epithelial integrity via suppressing the expression of p63, which is consistent with a role of EZH2 in restricting the basal cell lineage in the development of the lung. ${ }^{67,68} p 63$ is a key gene implicated in the stratification of epithelium, as stratification is impaired and differentiation markers are absent in the skin of p63-deficient mice. ${ }^{69}$ In the mammary gland, overexpression of p63 in luminal cells reprograms them to the basal type. ${ }^{70}$ Because of the existence of alternative promoters, two classes of p63 proteins are translated (ie, TAp63 and $\Delta \mathrm{Np} 63$ ). ${ }^{71}$ In addition, the alternative splicing at the $\mathrm{C}$-terminus produces at least three isoforms $(\alpha, \beta$, and $\gamma)$. $^{71}$ The exact function of p63 isoforms in epithelial stratification remains controversial. In the epidermis, TAp63 has been found to drive the stratification and expression of KRT5 and KRT14. ${ }^{72}$ However, other reports indicate that $\Delta \mathrm{Np} 63$ may initiate stratification or expansion of the basal layer. $^{73-75}$ In the uterus, the role of p63 isoforms in epithelial stratification remains unknown. The data support the involvement of $\Delta \mathrm{Np} 63$ in uterine epithelial stratification in the absence of EZH2. On the basis of these findings, it is tempting to speculate that $p 63$ and other basal cell genes are up-regulated as a result of decreased $\mathrm{H} 3 \mathrm{~K} 27$ methylation on loss of EZH2, leading to the differentiation of basal-like cells in the uterus. However, the function of these cells in $E z h 2 \mathrm{cKO}$ mice remains unclear. Because uterine epithelia generally do not contain basal cells, the appearance of this cell type and the expression of basal cell-associated keratins in EZH2-depleted uteri may indicate altered differentiation of epithelial cells that normally 

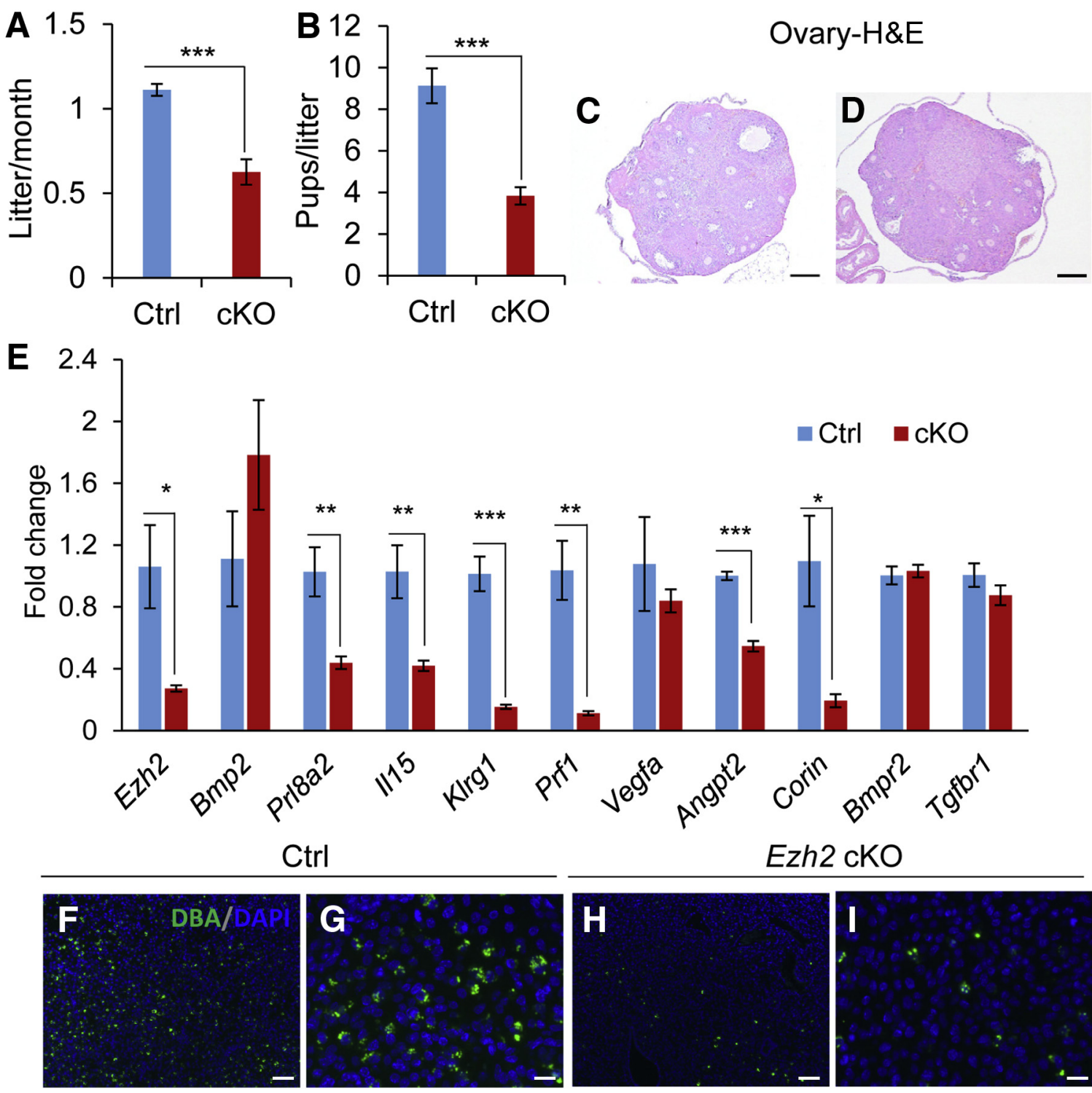

Figure 7 Reproductive defects in Ezh2 cK0 mice. A and B: Reduced number of litters and litter size during a 6-month fertility test. Approximately $64 \%$ of Ezh2 cKO mice, but not controls (Ctrls), developed signsed of dystocia or difficulty in labor during the fertility test. In that case, fertility parameters were calculated on the basis of data collected before mice developed the labor complication. $\mathbf{C}$ and $\mathbf{D}$ : Hematoxylin and eosin staining of ovaries from control and Ezh2 cKO mice at 2 months of age. E: Real-time PCR analysis of expression of genes associated with decidual differentiation, uterine natural killer (uNK) cells, and transforming growth factor- $\beta$ family signaling in embryonic day 8.5 (E8.5) decidual tissues from control and Ezh2 cKO mice. F-I: Reduction of uNK cells in E8.5 decidual basalis of Ezh2 cKO mice, evidenced by dolichos biflorus agglutinin (DBA) staining. $\mathbf{F}-\mathbf{I}$ : $\mathbf{F}$ and $\mathbf{H}$ are shown at higher magnification in $\mathbf{G}$ and $\mathbf{I}$, respectively. Data are expressed as means $\pm \operatorname{SEM}(\mathbf{A}, \mathbf{B}$, and $\mathbf{E}) . n=11$ (A and $\mathbf{B}, \mathrm{cKO}$ mice); $n=6(\mathbf{A}$ and $\mathbf{B}, \mathbf{C t r l}$ mice); $n=3(\mathbf{C}, \mathbf{D}, \mathbf{E}, \mathbf{C t r l}$ mice, and $\mathbf{F}-\mathbf{I})$; $n=4$ (E, cK0 mice). ${ }^{*} P<0.05,{ }^{*} P<0.01$, and ${ }^{* * *} P<0.001$. Scale bars: $250 \mu \mathrm{m}$ (C and $\left.\mathbf{D}\right) ; 100 \mu \mathrm{m}(\mathbf{F}$ and $\mathbf{H}) ; 25 \mu \mathrm{m}(\mathbf{G}$ and $\mathbf{I})$. Original magnification: $\times 40(\mathbf{C}$ and $\mathbf{D}) ; \times 100(\mathbf{F}$ and $\mathbf{H}) ; \times 400(\mathbf{G}$ and $\mathbf{I}) . \mathrm{H} \& \mathrm{E}$, hematoxylin and eosin staining.

form a simple epithelium in the uterus. As basal-like cells in the uterus are associated with uterine dysfunction and tumor progression, ${ }^{3,50}$ it is conceivable that epithelial stratification in $E z h 2 \mathrm{cKO}$ mice may link to the development of endometrial hyperplasia and/or reproductive deficiency.

Limitations exist for the current study. Because Pgr-Cre deletes genes in both epithelial and mesenchymal compartments, a potential contribution of epithelial-stromal interaction to the observed phenotype in Ezh2 cKO uteri should be considered. Future studies are needed to define how loss of EZH2 alters uterine growth and differentiation pathways and uncover the contribution of epithelial versus stromal EZH2 to the observed basal-like cell phenotype. Generation of Ezh2 conditional knockout mice using an epithelial- or stromal-specific Cre driver may help clarify this question. Ezh2 cKO female mice showed defects in parturition, the cause of which is unclear. Further investigations are warranted to gain mechanistic insights into this defect and determine whether EZH2 plays a role in the myometrium or cervix. It is also important to further define the epithelial versus stromal/decidual contribution to the observed reproductive defects. In addition, the methylation 
status of H3K27 of stratification-related genes (eg, p63, $K r t 14$, and Krt5) in uterine epithelial cells of Ezh2 cKO mice versus controls was not determined because of technical challenges of chromatin immunoprecipitation-realtime quantitative PCR assays using low amounts of uterine epithelial cells isolated from mice at an early developmental stage or using uterine tissues that contain multiple cell types. Nevertheless, the current findings reveal a novel role for uterine EZH2 in reproductive development and function.

Understanding of the role of EZH2 and EZH1 and their potential redundancy in establishing $\mathrm{H} 3 \mathrm{~K} 27$ methylation and gene silencing is incomplete. Our results clearly showed an EZH1-independent role of EZH2 in the regulation of endometrial homeostasis and integrity and uterine function, supporting that EZH1 and EZH2 may play distinct roles in maintaining the repressive chromatin. ${ }^{76}$ However, several studies indicate that EZH2 is not the only histone methyltransferase that establishes the H3K27 methylation mark. ${ }^{22,77,78}$ Instead, EZH1 and EZH2 function redundantly in regulating the methylation status of H3K27 during development. ${ }^{22,77,78}$ Generation and characterization of mice with compound loss of EZH2 and EZH1 in the uterus will help determine the functional overlap between the two genes, if any, and elucidate the role of histone modifications in the uterus.

In summary, results from the current study suggest that EZH2 maintains uterine epithelial integrity, partially through inhibiting the differentiation of basal-like cells and the development of endometrial hyperplasia. More important, the altered uterine growth and impaired fertility in the $E z h 2 \mathrm{cKO}$ mouse make it a useful model to understand mechanisms regulating endometrial homeostasis and uterine function. Our findings support the concept that manipulation of epigenetic regulators could offer an exquisite approach to treat reproductive diseases and fertility issues related to epigenetic changes or epigenetic drift, caused by environmental or intrinsic cues.

\section{Acknowledgments}

We thank Dr. Yang Gao (Baylor College of Medicine) for setting up the initial mouse breeding colony.

X.F. and N.N. performed the experiments and analyzed the data; J.P.L. generated and provided $P g r$-Cre mice; I.I., K.J.B., M.R., and Q.L. designed and supervised the work and offered guidance; X.F. and Q.L. wrote the manuscript; all authors provided valuable feedback on the final manuscript.

\section{Supplemental Data}

Supplemental material for this article can be found at http://doi.org/10.1016/j.ajpath.2019.02.016.

\section{References}

1. Li Q, Kannan A, DeMayo FJ, Lydon JP, Cooke PS, Yamagishi H, Srivastava D, Bagchi MK, Bagchi IC: The antiproliferative action of progesterone in uterine epithelium is mediated by Hand2. Science 2011, 331:912-916

2. Gao Y, Li S, Li Q: Uterine epithelial cell proliferation and endometrial hyperplasia: evidence from a mouse model. Mol Hum Reprod 2014, 20:776-786

3. Filant J, DeMayo FJ, Pru JK, Lydon JP, Spencer TE: Fibroblast growth factor receptor two (FGFR2) regulates uterine epithelial integrity and fertility in mice. Biol Reprod 2014, 90:7

4. Spencer TE: Biological roles of uterine glands in pregnancy. Semin Reprod Med 2014, 32:346-357

5. Filant J, Spencer TE: Endometrial glands are essential for blastocyst implantation and decidualization in the mouse uterus. Biol Reprod 2013, 88:93

6. Kelleher AM, Burns GW, Behura S, Wu G, Spencer TE: Uterine glands impact uterine receptivity, luminal fluid homeostasis and blastocyst implantation. Sci Rep 2016, 6:38078

7. Gray CA, Taylor KM, Ramsey WS, Hill JR, Bazer FW, Bartol FF, Spencer TE: Endometrial glands are required for preimplantation conceptus elongation and survival. Biol Reprod 2001, 64:1608-1613

8. Kelleher AM, Peng W, Pru JK, Pru CA, DeMayo FJ, Spencer TE: Forkhead box a2 (FOXA2) is essential for uterine function and fertility. Proc Natl Acad Sci U S A 2017, 114:E1018-E1026

9. Schwartz YB, Pirrotta V: Polycomb silencing mechanisms and the management of genomic programmes. Nat Rev Genet 2007, 8:9-22

10. Sauvageau M, Sauvageau G: Polycomb group proteins: multi-faceted regulators of somatic stem cells and cancer. Cell Stem Cell 2010, 7: 299-313

11. Vire E, Brenner C, Deplus R, Blanchon L, Fraga M, Didelot C, Morey L, Van Eynde A, Bernard D, Vanderwinden JM, Bollen M, Esteller M, Di Croce L, de Launoit Y, Fuks F: The polycomb group protein EZH2 directly controls DNA methylation. Nature 2006, 439:871-874

12. Wei Y, Chen YH, Li LY, Lang J, Yeh SP, Shi B, Yang CC, Yang JY, Lin CY, Lai CC, Hung MC: CDK1-dependent phosphorylation of EZH2 suppresses methylation of $\mathrm{H} 3 \mathrm{~K} 27$ and promotes osteogenic differentiation of human mesenchymal stem cells. Nat Cell Biol 2011, 13:87-94

13. Cao R, Zhang Y: The functions of E(Z)/EZH2-mediated methylation of lysine 27 in histone H3. Curr Opin Genet Dev 2004, 14:155-164

14. Beguelin W, Rivas MA, Fernandez MTC, Teater M, Purwada A, Redmond D, Shen H, Challman MF, Elemento O, Singh A, Melnick AM: EZH2 enables germinal centre formation through epigenetic silencing of CDKN1A and an Rb-E2F1 feedback loop. Nat Commun 2017, 8:877

15. Yang QW, Nair S, Laknaur A, Ismail N, Diamond MP, Al-Hendy A: The polycomb group protein EZH2 impairs DNA damage repair gene expression in human uterine fibroids. Biol Reprod 2016, 94:69

16. Grimaldi G, Christian M, Steel JH, Henriet P, Poutanen M, Brosens JJ: Down-regulation of the histone methyltransferase EZH2 contributes to the epigenetic programming of decidualizing human endometrial stromal cells. Mol Endocrinol 2011, 25:1892-1903

17. Greathouse KL, Bredfeldt T, Everitt JI, Lin K, Berry T, Kannan K, Mittelstadt ML, Ho SM, Walker CL: Environmental estrogens differentially engage the histone methyltransferase EZH2 to increase risk of uterine tumorigenesis. Mol Cancer Res 2012, 10:546-557

18. Colon-Caraballo M, Monteiro JB, Flores I: H3K27me3 is an epigenetic mark of relevance in endometriosis. Reprod Sci 2015, 22: $1134-1142$

19. Oki S, Sone K, Oda K, Hamamoto R, Ikemura M, Maeda D, Takeuchi M, Tanikawa M, Mori-Uchino M, Nagasaka K, Miyasaka A, Kashiyama T, Ikeda Y, Arimoto T, Kuramoto H, WadaHiraike O, Kawana K, Fukayama M, Osuga Y, Fujii T: Oncogenic histone methyltransferase EZH2: a novel prognostic marker with therapeutic potential in endometrial cancer. Oncotarget 2017, 8: 40402-40411

20. Committee for the Update of the Guide for the Care and Use of Laboratory Animals: National Research Council: Guide for the Care and Use of Laboratory Animals: Eighth Edition. Washington, DC, National Academies Press, 2011 
21. Soyal SM, Mukherjee A, Lee KY, Li J, Li HG, DeMayo FJ, Lydon JP: Cre-mediated recombination in cell lineages that express the progesterone receptor. Genesis 2005, 41:58-66

22. Shen X, Liu Y, Hsu YJ, Fujiwara Y, Kim J, Mao X, Yuan GC, Orkin SH: EZH1 mediates methylation on histone H3 lysine 27 and complements EZH2 in maintaining stem cell identity and executing pluripotency. Mol Cell 2008, 32:491-502

23. Bigsby RM, Cooke PS, Cunha GR: A simple efficient method for separating murine uterine epithelial and mesenchymal cells. Am J Physiol 1986, 251:E630-E636

24. Gao Y, Lin P, Lydon JP, Li Q: Conditional abrogation of transforming growth factor-beta receptor 1 in PTEN-inactivated endometrium promotes endometrial cancer progression in mice. J Pathol 2017, 243:89-99

25. Nagashima T, Li Q, Clementi C, Lydon JP, Demayo FJ, Matzuk MM: BMPR2 is required for postimplantation uterine function and pregnancy maintenance. J Clin Invest 2013, 123:2539-2550

26. Fang X, Ni N, Gao Y, Vincent DF, Bartholin L, Li Q: A novel mouse model of testicular granulosa cell tumors. Mol Hum Reprod 2018, 24 : 343-356

27. Li Q, Agno JE, Edson MA, Nagaraja AK, Nagashima T, Matzuk MM: Transforming growth factor beta receptor type 1 is essential for female reproductive tract integrity and function. PLoS Genet 2011, 7:e1002320

28. Paffaro VA Jr, Bizinotto MC, Joazeiro PP, Yamada AT: Subset classification of mouse uterine natural killer cells by DBA lectin reactivity. Placenta 2003, 24:479-488

29. Gao Y, Bayless KJ, Li Q: TGFBR1 is required for mouse myometrial development. Mol Endocrinol 2014, 28:380-394

30. Guo C, Balsara ZR, Hill WG, Li X: Stage- and subunit-specific functions of polycomb repressive complex 2 in bladder urothelial formation and regeneration. Development 2017, 144:400-408

31. Gu J, Lu Y, Qiao L, Ran D, Li N, Cao H, Gao Y, Zheng Q: Mouse p63 variants and chondrogenesis. Int J Clin Exp Pathol 2013, 6: 2872-2879

32. Reardon SN, King ML, MacLean JA, Mann JL, DeMayo FJ, Lydon JP, Hayashi K: Cdh1 is essential for endometrial differentiation, gland development, and adult function in the mouse uterus. Biol Reprod 2012, 86:141

33. Ni N, Gao Y, Fang X, Melgar M, Vincent DF, Lydon JP, Bartholin L, Li QL: Glandular defects in the mouse uterus with sustained activation of TGF-beta signaling is associated with altered differentiation of endometrial stromal cells and formation of stromal compartment. PLoS One 2018, 13:e209417

34. Guenzl PM, Raim R, Kral J, Brunner J, Sahin E, Schabbauer G: Insulin hypersensitivity induced by hepatic PTEN gene ablation protects from murine endotoxemia. PLoS One 2013, 8:e67013

35. Gao Y, Duran S, Lydon JP, DeMayo FJ, Burghardt RC, Bayless KJ, Bartholin L, Li Q: Constitutive activation of transforming growth factor beta receptor 1 in the mouse uterus impairs uterine morphology and function. Biol Reprod 2015, 92:34

36. Cawthorn WP, Bree AJ, Yao Y, Du BW, Hemati N, MartinezSantibanez G, MacDougald OA: Wnt6, Wnt10a and Wnt10b inhibit adipogenesis and stimulate osteoblastogenesis through a beta-catenindependent mechanism. Bone 2012, 50:477-489

37. Mori H, Prestwich TC, Reid MA, Longo KA, Gerin I, Cawthorn WP, Susulic VS, Krishnan V, Greenfield A, Macdougald OA: Secreted frizzled-related protein 5 suppresses adipocyte mitochondrial metabolism through WNT inhibition. J Clin Invest 2012, 122:2405-2416

38. Fisher DA, Kivimae S, Hoshino J, Suriben R, Martin PM, Baxter N, Cheyette BN: Three Dact gene family members are expressed during embryonic development and in the adult brains of mice. Dev Dyn 2006, 235:2620-2630

39. Gao Y, Wen H, Wang C, Li Q: SMAD7 antagonizes key TGFbeta superfamily signaling in mouse granulosa cells in vitro. Reproduction 2013, 146:1-11
40. Spandidos A, Wang XW, Wang HJ, Seed B: PrimerBank: a resource of human and mouse PCR primer pairs for gene expression detection and quantification. Nucleic Acids Res 2010, 38:D792-D799

41. Song GA, Kim HJ, Woo KM, Baek JH, Kim GS, Choi JY, Ryoo HM: Molecular consequences of the ACVR1(R206H) mutation of fibrodysplasia ossificans progressiva. J Biol Chem 2010, 285:22542-22553

42. Segers I, Adriaenssens T, Wathlet S, Smitz J: Gene expression differences induced by equimolar low doses of LH or hCG in combination with FSH in cultured mouse antral follicles. J Endocrinol 2012, 215:269-280

43. Livak KJ, Schmittgen TD: Analysis of relative gene expression data using real-time quantitative PCR and the 2(-Delta Delta $\mathrm{C}(\mathrm{T})$ ) method. Methods 2001, 25:402-408

44. Gan L, Xu M, Hua R, Tan C, Zhang J, Gong Y, Wu Z, Weng W, Sheng W, Guo W: The polycomb group protein EZH2 induces epithelial-mesenchymal transition and pluripotent phenotype of gastric cancer cells by binding to PTEN promoter. J Hematol Oncol 2018, 11 :9

45. Bragulla HH, Homberger DG: Structure and functions of keratin proteins in simple, stratified, keratinized and cornified epithelia. J Anat 2009, 214:516-559

46. Silverberg SG: Problems in the differential diagnosis of endometrial hyperplasia and carcinoma. Mod Pathol 2000, 13:309-327

47. Sanderson PA, Critchley HO, Williams AR, Arends MJ, Saunders PT: New concepts for an old problem: the diagnosis of endometrial hyperplasia. Hum Reprod Update 2017, 23:232-254

48. Franco HL, Dai D, Lee KY, Rubel CA, Roop D, Boerboom D, Jeong JW, Lydon JP, Bagchi IC, Bagchi MK, DeMayo FJ: WNT4 is a key regulator of normal postnatal uterine development and progesterone signaling during embryo implantation and decidualization in the mouse. FASEB J 2011, 25:1176-1187

49. Miller C, Sassoon DA: Wnt-7a maintains appropriate uterine patterning during the development of the mouse female reproductive tract. Development 1998, 125:3201-3211

50. Liang XH, Daikoku T, Terakawa J, Ogawa Y, Joshi AR, Ellenson LH, Sun XF, Dey SK: The uterine epithelial loss of Pten is inefficient to induce endometrial cancer with intact stromal Pten. PLoS Genet 2018, 14:e1007630

51. Wang $\mathrm{P}$, Wu SP, Brooks KE, Kelleher AM, Milano-Foster JJ, DeMayo FJ, Spencer TE: Generation of mouse for conditional expression of forkhead box A2. Endocrinology 2018, 159:1897-1909

52. Filant J, Lydon JP, Spencer TE: Integrated chromatin immunoprecipitation sequencing and microarray analysis identifies FOXA2 target genes in the glands of the mouse uterus. FASEB J 2014, 28 : 230-243

53. Lee KY, Jeong JW, Wang J, Ma L, Martin JF, Tsai SY, Lydon JP, DeMayo FJ: Bmp2 is critical for the murine uterine decidual response. Mol Cell Biol 2007, 27:5468-5478

54. Ramathal CY, Bagchi IC, Taylor RN, Bagchi MK: Endometrial decidualization: of mice and men. Semin Reprod Med 2010, 28: $17-26$

55. Benson GV, Lim H, Paria BC, Satokata I, Dey SK, Maas RL: Mechanisms of reduced fertility in Hoxa-10 mutant mice: uterine homeosis and loss of maternal Hoxa-10 expression. Development 1996, 122:2687-2696

56. Matsumoto H, Sato E: Uterine angiogenesis during implantation and decidualization in mice. Reprod Med Biol 2006, 5:81-86

57. Gellersen B, Brosens IA, Brosens JJ: Decidualization of the human endometrium: mechanisms, functions, and clinical perspectives. Semin Reprod Med 2007, 25:445-453

58. Cui Y, Wang W, Dong N, Lou J, Srinivasan DK, Cheng W, Huang X, Liu M, Fang C, Peng J, Chen S, Wu S, Liu Z, Dong L, Zhou Y, Wu Q: Role of corin in trophoblast invasion and uterine spiral artery remodelling in pregnancy. Nature 2012, 484:246-250

59. Peng J, Monsivais D, You R, Zhong H, Pangas SA, Matzuk MM: Uterine activin receptor-like kinase 5 is crucial for blastocyst implantation and placental development. Proc Natl Acad Sci U S A 2015, 112:E5098-E5107 
60. Yamaguchi H, Hung MC: Regulation and role of EZH2 in cancer. Cancer Res Treat 2014, 46:209-222

61. Gu Y, Zhang J, Guan H: Expression of EZH2 in endometrial carcinoma and its effects on proliferation and invasion of endometrial carcinoma cells. Oncol Lett 2017, 14:7191-7196

62. Zhang Q, Dong P, Liu X, Sakuragi N, Guo SW: Enhancer of zeste homolog 2 (EZH2) induces epithelial-mesenchymal transition in endometriosis. Sci Rep 2017, 7:6804

63. Ding YB, Long CL, Liu XQ, Chen XM, Guo LR, Xia YY, He JL, Wang YX: 5-Aza-2'-deoxycytidine leads to reduced embryo implantation and reduced expression of DNA methyltransferases and essential endometrial genes. PLoS One 2012, 7:e45364

64. O'Carroll D, Erhardt S, Pagani M, Barton SC, Surani MA, Jenuwein T: The polycomb-group gene Ezh2 is required for early mouse development. Mol Cell Biol 2001, 21:4330-4336

65. Dunlap KA, Filant J, Hayashi K, Rucker EB 3rd, Song G, Deng JM, Behringer RR, DeMayo FJ, Lydon J, Jeong JW, Spencer TE: Postnatal deletion of Wnt7a inhibits uterine gland morphogenesis and compromises adult fertility in mice. Biol Reprod 2011, 85:386-396

66. Jeong JW, Lee HS, Franco HL, Broaddus RR, Taketo MM, Tsai SY, Lydon JP, DeMayo FJ: beta-Catenin mediates glandular formation and dysregulation of beta-catenin induces hyperplasia formation in the murine uterus. Oncogene 2009, 28:31-40

67. Snitow ME, Li S, Morley MP, Rathi K, Lu MM, Kadzik RS, Stewart KM, Morrisey EE: Ezh2 represses the basal cell lineage during lung endoderm development. Development 2015, 142:108-117

68. Galvis LA, Holik AZ, Short KM, Pasquet J, Lun AT, Blewitt ME, Smyth IM, Ritchie ME, Asselin-Labat ML: Repression of Igf1 expression by Ezh2 prevents basal cell differentiation in the developing lung. Development 2015, 142:1458-1469

69. Mills AA, Zheng BH, Wang XJ, Vogel H, Roop DR, Bradley A: p63 Is a p53 homologue required for limb and epidermal morphogenesis. Nature 1999, 398:708-713
70. Yalcin-Ozuysal O, Fiche M, Guitierrez M, Wagner KU, Raffoul W, Brisken C: Antagonistic roles of Notch and p63 in controlling mammary epithelial cell fates. Cell Death Differ 2010, 17:1600-1612

71. Murray-Zmijewski F, Lane DP, Bourdon JC: p53/p63/p73 Isoforms: an orchestra of isoforms to harmonise cell differentiation and response to stress. Cell Death Differ 2006, 13:962-972

72. Koster MI, Kim S, Mills AA, DeMayo FJ, Roop DR: p63 Is the molecular switch for initiation of an epithelial stratification program. Genes Dev 2004, 18:126-131

73. Candi E, Rufini A, Terrinoni A, Dinsdale D, Ranalli M, Paradisi A, De Laurenzi V, Spagnoli LG, Catani MV, Ramadan S, Knight RA, Melino G: Differential roles of p63 isoforms in epidermal development: selective genetic complementation in p63 null mice. Cell Death Differ 2006, 13:1037-1047

74. Laurikkala J, Mikkola ML, James M, Tummers M, Mills AA, Thesleff I: p63 Regulates multiple signalling pathways required for ectodermal organogenesis and differentiation. Development 2006, 133:1553-1563

75. Romano RA, Ortt K, Birkaya B, Smalley K, Sinha S: An active role of the DeltaN isoform of p63 in regulating basal keratin genes K5 and K14 and directing epidermal cell fate. PLoS One 2009, 4: e5623

76. Margueron R, Li GH, Sarma K, Blais A, Zavadil J, Woodcock CL, Dyniacht BD, Reinberg D: Ezh1 and Ezh2 maintain repressive chromatin through different mechanisms. Mol Cell 2008, 32:503-518

77. Ezhkova E, Lien WH, Stokes N, Pasolli HA, Silva JM, Fuchs E: EZH1 and EZH2 cogovern histone H3K27 trimethylation and are essential for hair follicle homeostasis and wound repair. Genes Dev 2011, 25:485-498

78. Ezhkova E, Pasolli HA, Parker JS, Stokes N, Su IH, Hannon G, Tarakhovsky A, Fuchs E: Ezh2 orchestrates gene expression for the stepwise differentiation of tissue-specific stem cells. Cell 2009, 136: $1122-1135$ 